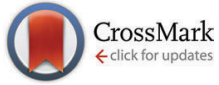

Cite this: Chem. Commun., 2014 50, 15202

Received 23rd September 2014 Accepted 17th October 2014

DOI: $10.1039 / c 4 c c 07487 d$

www.rsc.org/chemcomm

\section{Ligand selectivity in stabilising tandem parallel folded G-quadruplex motifs in human telomeric DNA sequences}

\author{
Alex R. O. Cousins, ${ }^{\text {ab }}$ Dougal Ritson, ${ }^{b}$ Pallavi Sharma, ${ }^{b}$ Malcolm F. G. Stevens, ${ }^{c}$ \\ John E. Moses ${ }^{b}$ and Mark S. Searle*ab
}

Biophysical studies of ligand interactions with three human telomeric repeat sequences (d(AGGG(TTAGGG) $n=3,7$ and 11)) show that an oxazole-based 'click' ligand, which induces parallel folded quadruplexes, preferentially stabilises longer telomeric repeats providing evidence for selectivity in binding at the interface between tandem quadruplex motifs.

The prevalence of guanine-rich sequences throughout the human genome, coupled with their ability in vitro to adopt stable folded quadruplex structures in the presence of physiological concentrations of monovalent cations, suggests that this structural motif serves a wide functional role in regulating gene expression, ${ }^{1-5}$ making quadruplexes potential therapeutic targets. ${ }^{6-8}$ More specifically, telomeres, which are found at the ends of chromosomes, are composed of 150-250 nucleotides of d(TTAGGG) repeats and play a critical role in limiting cell proliferation by shortening with each round of replication. ${ }^{9}$ The up-regulation of the enzyme telomerase (hTERT) in the majority of cancer cell lines serves to stabilise the length of the telomere and extend the replicative potential. The activity of hTERT is dependent upon a singlestranded template for sequence extension, making the stabilisation of compact telomeric quadruplex structures fertile ground for the design of small molecule telomerase inhibitors. ${ }^{6-8}$

The single-stranded telomere has the potential to adopt multiple quadruplex structures in the manner of a series of 'beads on a string'. The extent to which interactions between these adjacent or tandem quadruplex 'beads' can result in the formation of higherorder capping structures may have some relevance in protecting DNA double-strand ends from being recognised as strand breaks, and in activating DNA damage-repair mechanisms. Evidence suggests that extensive quadruplex formation within the telomeric

\footnotetext{
${ }^{a}$ Centre for Biomolecular Sciences, University Park, University of Nottingham, Nottingham NG7 2RD, UK. E-mail: mark.searle@nottingham.ac.uk

${ }^{b}$ School of Chemistry, University Park, University of Nottingham, Nottingham NG7 2RD, UK

${ }^{c}$ School of Pharmacy, University Park, University of Nottingham, Nottingham NG7 2RD, UK
}

sequence induces strong exonuclease resistance, constituting an effective protection mechanism against hydrolysis. ${ }^{10}$

Although interfacial interactions between proximal quadruplex motifs have been proposed on the basis of spectroscopic analysis and modelling studies, ${ }^{11,12}$ the stability of folded telomeres appears to be inversely correlated with their length, indicating that steric and electrostatic repulsions between folded motifs result in destabilising interactions. ${ }^{11-14}$ Model building from X-ray structures has suggested the possibility of ligand-binding pockets at these interfacial sites employing both G-tetrad stacking and contacts with $\mathrm{A} / \mathrm{T}$ nucleotides within the conformationally flexible loops. ${ }^{15}$ However, the extent to which these 'loose' interfaces could provide novel targets for ligand design and binding has remained largely unexplored, and experimental evidence that ligands can bind selectively at the interface between quadruplex motifs, and target telomeric DNA sequences, is still lacking.

We have characterised the folding and stability of the human telomeric repeat sequence $5^{\prime}$-AGGG(TTAGGG) $)_{n}$, for $n=3$ (HT), $7\left(\mathrm{HT}^{2}\right)$ and $11\left(\mathrm{HT}^{3}\right)$, in detail using circular dichroism (CD) spectroscopy in buffered $\mathrm{K}^{+}$solution at $\mathrm{pH} 7.0{ }^{14}$ The three sequences are capable of forming either a single quadruplex motif, or two or three in tandem. In agreement with previous studies, ${ }^{12,13}$ the thermal stabilities decrease across the series (solid lines in Fig. 2) with a depression of the $T_{\mathrm{m}}$ of the trimer $\left(\mathrm{HT}^{3}\right)$ by $\sim 8-9{ }^{\circ} \mathrm{C}$ below that of the single monomer (HT) (see Table 1). The CD spectral features, backed-up by NMR structural analysis, are consistent with the formation of $(3+1)$ hybrid antiparallel motifs, which appear to be sterically destabilised by

Table 1 Quadruplex stability measurements from CD melting curves with and without bound ligands

\begin{tabular}{lllll}
\hline Sequence & $\begin{array}{l}T_{\mathrm{m}}\left(\mathrm{K}^{+}\right)^{a} \\
\text { no ligand }\end{array}$ & $\begin{array}{l}T_{\mathrm{m}}\left(\mathrm{K}^{+}\right)^{a}+ \\
\text { RHPS4 }\end{array}$ & $\begin{array}{l}T_{\mathrm{m}}\left(\mathrm{K}^{+}\right)^{a}+ \\
\text { DR4-47 }\end{array}$ & $\begin{array}{l}T_{\mathrm{m}}\left(\mathrm{Na}^{+}\right)^{b}+ \\
\text { DR4-47 }\end{array}$ \\
\hline $\mathrm{HT}$ & $69.3 \pm 0.1$ & $86.6 \pm 0.1$ & $83.5 \pm 0.1$ & $72.0 \pm 0.5$ \\
$\mathrm{HT}^{2}$ & $61.5 \pm 0.1$ & $82.0 \pm 0.1$ & $>90$ & $84.0 \pm 0.5$ \\
$\mathrm{HT}^{3}$ & $60.9 \pm 0.1$ & $74.7 \pm 0.1$ & $>95$ & $82.0 \pm 0.5$
\end{tabular}

$a_{100 \mathrm{mM} \mathrm{KCl}, 10 \mathrm{mM} \mathrm{K}} \mathrm{HPO}_{4} / \mathrm{KH}_{2} \mathrm{PO}_{4}$, pH 7. ${ }^{b} 100 \mathrm{mM} \mathrm{NaCl}, 10 \mathrm{mM}$ $\mathrm{Na}_{2} \mathrm{HPO}_{4} / \mathrm{NaH}_{2} \mathrm{PO}_{4}, \mathrm{pH} 7$. 


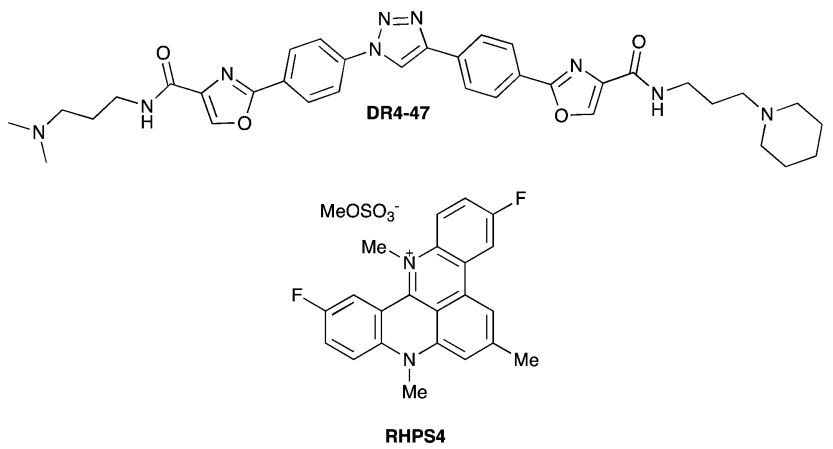

Fig. 1 Structure of G-quadruplex ligands RHPS4 and DR4-47.

nearest neighbour interactions. ${ }^{12}$ These studies conclude that the stabilities, but not the structures, show sequence-dependent changes which we investigate further in the context of two quadruplex binding ligands with quite different structural architectures and hence binding selectivities.

We have previously shown that the fluoroquinolinoacridinium cation RHPS4 (Fig. 1) binds to AGGG(TTAGGG) ${ }_{3}$ and induces changes in the CD spectrum ${ }^{16}$ which are consistent with the features reported for the basket-type $(2+2)$ anti-parallel structure observed in $\mathrm{Na}^{+}$solution, and characterised structurally by Wang and co-workers. ${ }^{17}$ The dimer and trimer quadruplex sequences $\mathrm{HT}^{2}$ and $\mathrm{HT}^{3}$ showed analogous ligand induced interconversion to the $(2+2)$ basket-type fold. Sigmoidal thermal unfolding curves, recorded for solutions containing two equivalents of ligand per quadruplex (Fig. 2), resulted in large stabilising effects of between $14-21{ }^{\circ} \mathrm{C}$ (Table 1). The order of stability of the bound complexes mirrors the unbound telomeres $\left(\mathrm{HT}>\mathrm{HT}^{2}>\mathrm{HT}^{3}\right)$, suggesting that steric interactions between tandem quadruplex motifs continue to be destabilising in the ligand-bound state, despite the ligand-induced conformational switch.

We subsequently investigated the hybrid oxazole-triazole ligand DR4-47 (Fig. 1), designed as a quadruplex-selective binder. ${ }^{18}$ In contrast to RHPS4, CD analysis of DR4-47 showed ligand-induced

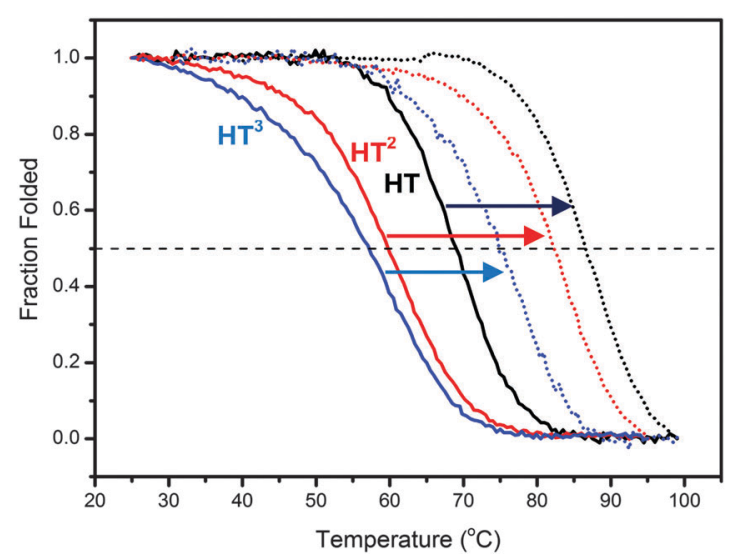

Fig. $2 \mathrm{CD}$ thermal unfolding profiles (at $290 \mathrm{~nm}$ ) for $\mathrm{HT}, \mathrm{HT}^{2}$ and $\mathrm{HT}^{3}$ (solid lines colour coded) and shifts (shown by arrows) when bound to RHPS4 (dotted lines) in $100 \mathrm{mM} \mathrm{KCl}, 10 \mathrm{mM} \mathrm{K} \mathrm{HPO}_{4} / \mathrm{KH}_{2} \mathrm{PO}_{4}, \mathrm{pH} 7$ with two equivalents of ligand per quadruplex $\left(\mathrm{HT}=3.83 \mu \mathrm{M}, \mathrm{HT}^{2}=1.53 \mu \mathrm{M}\right.$, $H T^{3}=0.61 \mu \mathrm{M}$ ).

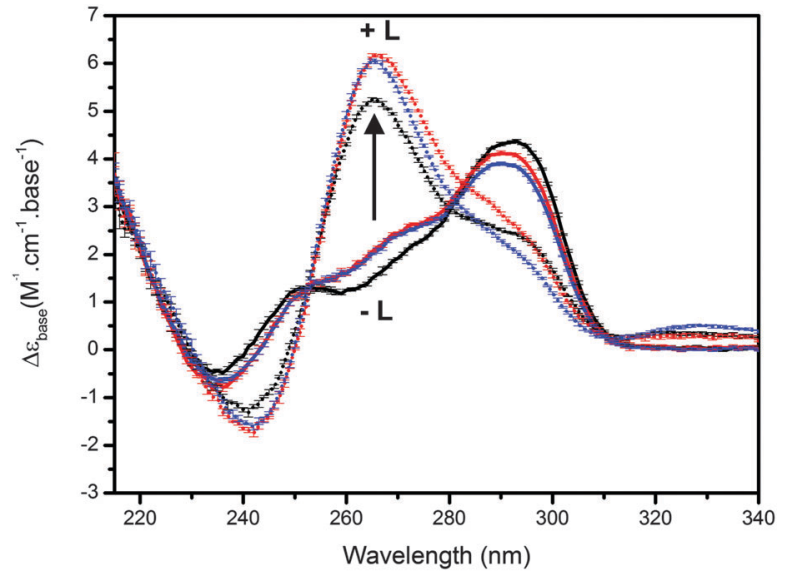

Fig. 3 Normalised $\mathrm{CD}$ spectra of $\mathrm{HT}, \mathrm{HT}^{2}$ and $\mathrm{HT}^{3}$ unbound (solid lines colour coded) in $100 \mathrm{mM} \mathrm{KCl}, 10 \mathrm{mM} \mathrm{K} \mathrm{HPO}_{4} / \mathrm{KH}_{2} \mathrm{PO}_{4}, \mathrm{pH} 7$ and in the presence of DR4-47 (dashed lines) at a 1:5 ratio, showing a large ligandinduced increase in ellipticity at $265 \mathrm{~nm}$ (arrow).

enhancement of the ellipticity at $262 \mathrm{~nm}$ in the spectrum of the HT sequence and a reduction at $290 \mathrm{~nm}$, both of which are indicative of a significant population of parallel stranded structures at equilibrium (Fig. 3). The same characteristic spectral changes were evident in DR4-47 titration studies with $\mathrm{HT}^{2}$ and $\mathrm{HT}^{3}$, with a high proportion of parallel-folded structure evident at a quadruplex: ligand ratio of $1: 5$ (Fig. 3).

Thermal unfolding experiments (monitored at $260 \mathrm{~nm}$ ) revealed a quite different trend in relative stabilities compared to the unbound telomeric sequences (Fig. 4). While the sigmoidal melting profile for the complex with HT is well defined, the profiles for $\mathrm{HT}^{2}$ and $\mathrm{HT}^{3}$ are incomplete at $\sim 100{ }^{\circ} \mathrm{C}$, indicating that the longer telomeres are still partially folded at this temperature showing preferential stabilisation of the ligand-induced arrangement of tandem parallel folded quadruplexes. ${ }^{19}$

We tested these observations further by changing to buffered $\mathrm{Na}^{+}$ solutions (100 mM NaCl, $10 \mathrm{mM} \mathrm{Na} \mathrm{HPO}_{4} / \mathrm{NaH}_{2} \mathrm{PO}_{4}, \mathrm{pH}$ 7) where quadruplex stabilities are lower. All three telomeric sequences showed clear evidence of a conformational shift to the $(2+2)$ antiparallel basket structure characterised by a strong negative ellipticity at $265 \mathrm{~nm}$ in the CD spectra (Fig. 5). Ligand titration studies

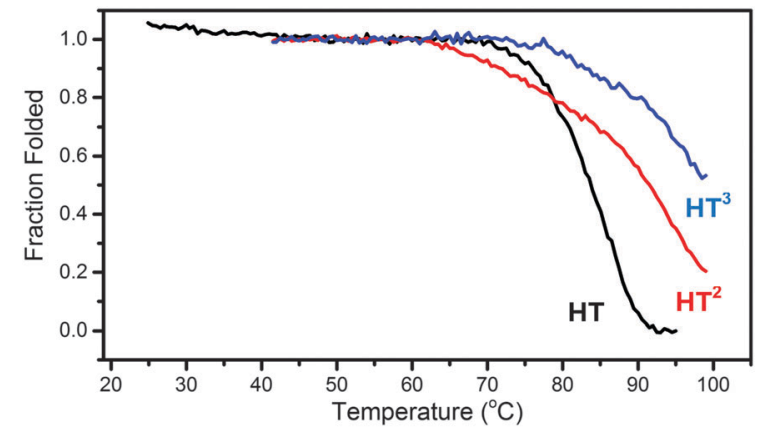

Fig. $4 \mathrm{CD}$ thermal stability profiles for $\mathrm{HT}, \mathrm{HT}^{2}$ and $\mathrm{HT}^{3}$ at a fixed ratio of $1: 3.4$ of quadruplex motif to DR4-47 in $100 \mathrm{mM} \mathrm{KCl}, 10 \mathrm{mM} \mathrm{K}_{2} \mathrm{HPO}_{4} /$ $\mathrm{KH}_{2} \mathrm{PO}_{4}, \mathrm{pH} 7$. 


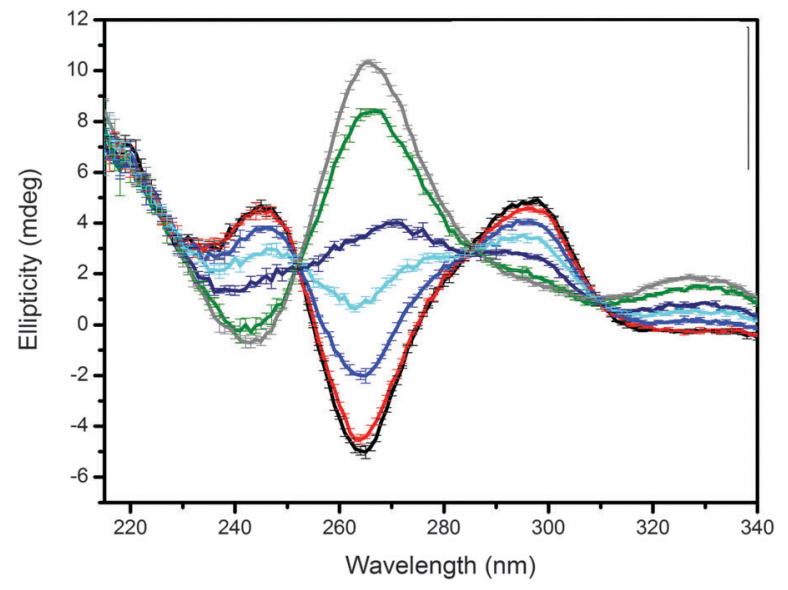

Fig. $5 \mathrm{CD}$ studies showing the titration of $\mathrm{HT}$ (in $100 \mathrm{mM} \mathrm{NaCl}, 10 \mathrm{mM}$ $\mathrm{Na}_{2} \mathrm{HPO}_{4} / \mathrm{NaH}_{2} \mathrm{PO}_{4}, \mathrm{pH} 7$ solution) with DR4-47 and the conformational shift to the parallel folded structure associated with an increase in positive ellipticity at $265 \mathrm{~nm}$.

under identical conditions revealed the same shift towards parallel folded structures observed in $\mathrm{K}^{+}$solutions, with the negative band at $265 \mathrm{~nm}$ becoming increasingly positive at increasing ligand : quadruplex ratios (Fig. 5). Isodichroic points at 252, 285 and $310 \mathrm{~nm}$ are consistent with interconversion between two well-defined quadruplex topologies.

The changes in the spectral features during ligand titrations in both $\mathrm{K}^{+}$and $\mathrm{Na}^{+}$buffered solutions show very similar conformational transitions, supporting the notion that ligand binding strongly favours the parallel folded structure irrespective of any intrinsic structural preference of the sequence under the prevailing ionic conditions. The overall decrease in stability in $\mathrm{Na}^{+}$solution brings all three $\mathrm{CD}$ melting curves into an accessible temperature range (Fig. 6), and confirms the observations in $\mathrm{K}^{+}$buffered solutions that the longer telomeric repeat sequences are preferentially stabilised over the monomeric quadruplex motif (HT).

We used molecular dynamics (MD) simulations ${ }^{11,12}$ to investigate different modes of interaction that could account for the

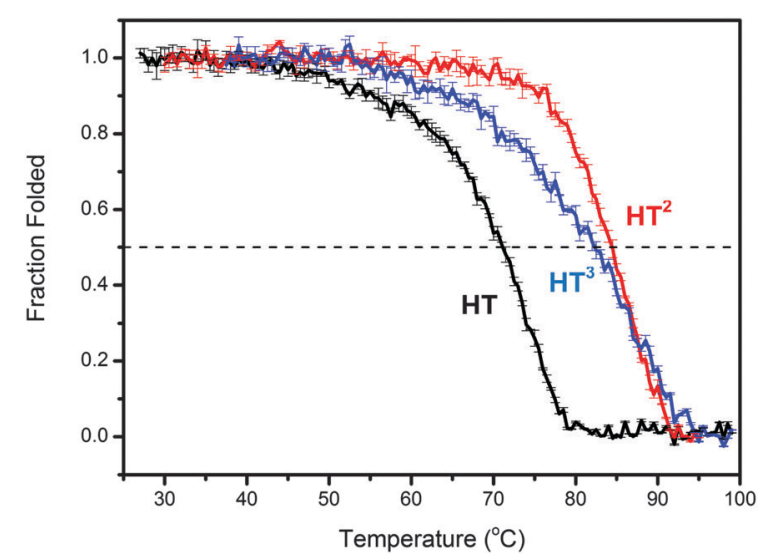

Fig. $6 \mathrm{CD}$ melting profiles for $\mathrm{HT}, \mathrm{HT}^{2}$ and $\mathrm{HT}^{3}$ in the presence of DR4-47 (100 mM NaCl, $10 \mathrm{mM} \mathrm{Na}_{2} \mathrm{HPO}_{4} / \mathrm{NaH}_{2} \mathrm{PO}_{4}$ at $\mathrm{pH}$ 7.0) showing preferential stabilisation of the dimer and trimer over the single quadruplex motif. (a)

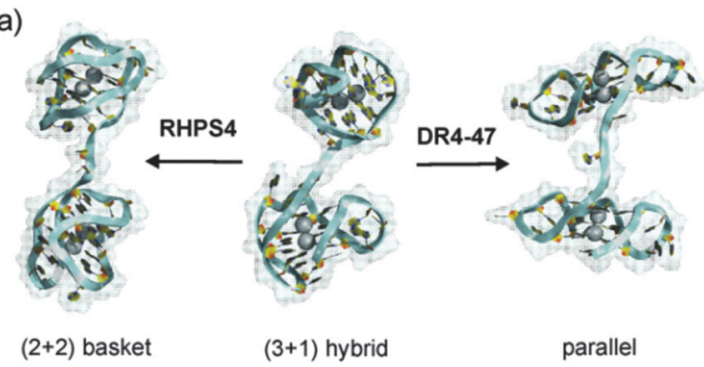

(b)

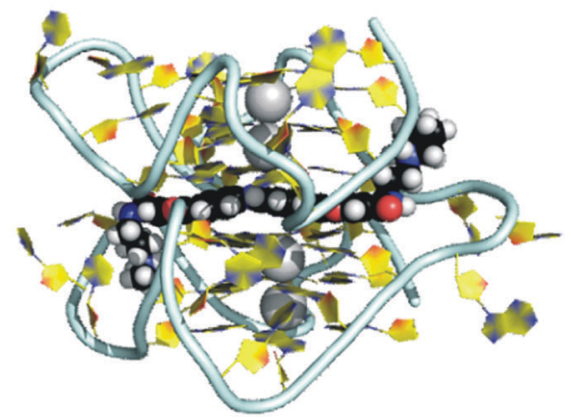

Fig. 7 (a) Structure of $\mathrm{HT}^{2}$ from MD simulations showing the $(3+1)$ hybrid structure and ligand-induced $(2+2)$ basket (RHPS4) and parallel (DR4-47) structures. (b) Model of the DR4-47 complex with $\mathrm{HT}^{2}$ showing a sandwich $\pi$-stacking complex of the ligand with flexible arms extending into the grooves of both quadruplexes simultaneously.

preferential stabilisation of tandem parallel folded quadruplex motifs. Structures of DR4-47 were subjected to geometry optimisation with Gaussian 03 and the ligand manually docked into various plausible orientations that allowed for $\pi$-stacking interactions at the ends of the quadruplex. ${ }^{20}$ These included a sandwich complex between the two quadruplexes of $\mathrm{HT}^{2}$ with the formation of stacking interactions with G-tetrads at the ends of both motifs simultaneously. This complex, and other 'open' conformations, was stable during short $2 \mathrm{~ns}$ MD simulations. In the sandwich complex (Fig. 7), the mobile divergent 'arms' of the ligand were able to interact with the grooves of the two quadruplex motifs simultaneously in a number of different conformations via dynamic contacts. This sterically plausible model, which remains to be experimentally verified, suggests stabilising contacts between the different quadruplex loop sequences which are offset to minimise steric repulsions.

In conclusion, telomeric DNA, consisting of multiple repeats of d(TTAGGG $)_{n}$, is a validated drug target for the inhibition of telomerase through the stabilisation of quadruplex motifs. ${ }^{6-8}$ To date, drug design has focused on the targeting of single quadruplexes, primarily through $\pi$-stacking on the terminal G-tetrads. ${ }^{6-8}$ Telomeric sequences are known to be highly polymorphic and quadruplex binding ligands have been shown to induce different conformations within these individual structural motifs. ${ }^{16}$

Here, we report biophysical studies of two quadruplex-selective ligands binding to telomeric sequences which form multiple (two or three) quadruplex motifs in series. We have demonstrated that a hybrid oxazole-triazole ligand ${ }^{16,18}$ induces parallel-folded structure which leads to preferential stabilisation of longer telomeric 
sequences where quadruplex motifs are formed in tandem. In contrast, the quinoacridinium cation (RHPS4) enforces a largely anti-parallel fold which, although significantly stabilising at the level of the individual quadruplex motif $\left(\Delta T_{\mathrm{m}} \sim 15-20{ }^{\circ} \mathrm{C}\right)$, shows no evidence for preferential stabilisation of the longer sequences. MD simulations suggest a plausible structural model for the DR4-47 complex in which the ligand is sandwiched between tandem quadruplexes through $\pi$-stacking with the terminal G-tetrads, with additional groove contacts involving electrostatic interactions (Fig. 7). Alternative models have suggested that a TATA tetrad formed between loop residues could also provide the basis for ligand stacking interactions at the interface. ${ }^{15}$ We have now shown evidence amongst at least one group of ligands for selectivity in binding at this unique site through induction of a parallel folded conformation in the highly polymorphic human telomeric DNA sequence.

We thank Worldwide Cancer Research (Formerly known as AICR) for financial support to DR and JEM (AICR ref: 06-0539) and to AROC, MSS and JEM (AICR ref: 09-0591).

\section{Notes and references}

1 J. Huppert and S. Balasubramanian, Nucleic Acids Res., 2005, 33, 2908; A. Todd, M. Johnston and S. Neidle, Nucleic Acids Res., 2005, 33, 2901.

2 H. J. Lipps and D. Rhodes, Trends Cell Biol., 2009, 19, 414; T. A. Brooks and L. H. Hurley, Genes Cancer, 2010, 1, 641; T. Fletcher, D. Sun, M. Salazar and L. H. Hurley, Biochemistry, 1998, 37, 5536.

3 J. Mergny, J. Riou, P. Mailliet, M. Teulade-Fichou and E. Gilson, Nucleic Acids Res., 2002, 30, 839; R. De Armond, S. Wood, D. Sun, L. H. Hurley and S. W. Ebinghaus, Biochemistry, 2005, 44, 16341.

4 S. Kumari, A. Bugaut and S. Balasubramanian, Biochemistry, 2008, 47, 12664; H. Fernando, A. P. Reszka, J. Huppert, S. Ladame, S. Rankin, A. R. Venkitaraman, S. Neidle and S. Balasubramanian, Biochemistry, 2006, 45, 7854; G. Biffi, D. Tannahill, J. McCafferty and S. Balasubramanian, Nat. Chem., 2013, 5, 182.

5 G. D. Balkwill, K. Derecka, T. P. Garner, C. Hodgman, A. P. F. Flint and M. S. Searle, Biochemistry, 2010, 48, 11487.

6 S. Neidle and G. Parkinson, Nat. Rev. Drug Discovery, 2002, 1, 383; M. Bejugam, S. Sewitz, P. S. Shirude, R. Rodriguez, R. Shahid and S. Balasubramanian, J. Am. Chem. Soc., 2007, 129, 12926.

7 C. Grand, H. Han, R. Munoz and L. H. Hurley, Mol. Cancer Ther., 2002, 1, 565; A. Siddiqui-Jain, C. L. Grand, D. J. Bears and
L. H. Hurley, Proc. Natl. Acad. Sci. U. S. A., 2002, 99, 11593; A. De Cian, L. Lacroix, C. Douarre, N. Temime-Smaali, C. Trentesaux, J.-F. Rioux and J.-L. Mergny, Biochimie, 2008, 90, 131.

8 M. S. Searle and G. D. Balkwill, in Quadruplex Nucleic Acids, ed. S. Neidle and S. Balasubramanian, Royal Society of Chemistry Publishing, Cambridge, UK, 2007, p. 131.

9 N. W. Kim, M. A. Piatyszek, K. R. Prowse, C. B. Harley, M. D. West, P. L. C. Ho, G. M. Coviello, W. E. Wright, S. L. Weinrich and J. W. Shay, Science, 1994, 266, 2011; J. Lingner, T. R. Hughes, A. Shevchenko, M. Mann, V. Lundblad and T. R. Cech, Science, 1997, 276, 561; T. M. Nakamura, G. B. Morin, K. B. Chapman, S. L. Weinrich, W. H. Andrews, J. Lingner, C. B. Harley and T. R. Cech, Science, 1997, 277, 955; J. L. Feng, W. D. Funk, S. S. Wang, S. L. Weinrich, A. A. Avilion, C. P. Chiu, R. R. Adams, E. Chang, R. C. Allsopp, J. H. Yu, S. Y. Le, M. D. West, C. B. Harley, W. H. Andrews, C. W. Greider and B. Villeponteau, Science, 1995, 269, 1236.

10 Y. Xu, T. Ishizuka, K. Kurabayashi and M. Komiyama, Angew. Chem., Int. Ed., 2009, 48, 7833.

11 L. Petraccone, N. C. Garbett, J. B. Chaires and J. O. Trent, Biopolymers, 2010, 93, 533.

12 L. Petraccone, C. Spink, J. O. Trent, N. C. Garbett, C. S. Mekmaysy, C. Giancola and J. B. Chaires, J. Am. Chem. Soc., 2011, 133, 20951.

13 M. Vorlickova, J. Chladkova, I. Kejnovska, M. Fialova and J. Typr, Nucleic Acids Res., 2005, 33, 5851; D. Renciuk, I. Kejnovska, P. Skolakova, K. Bednarova, J. Motlova and M. Vorlickova, Nucleic Acids Res., 2009, 37, 6635; A. Randall and J. D. Griffith, J. Biol. Chem., 2009, 284, 13980.

14 A. R. O. Cousins, PhD thesis, University of Nottingham, 2014.

15 S. M. Haider and S. Neidle, Biochem. Soc. Trans., 2009, 37, 583.

16 T. P. Garner, H. E. L. Williams, K. I. Gluszyk, S. Roe, N. J. Oldham, M. G. Stevens, J. E. Moses and M. S. Searle, Org. Biomol. Chem., 2009, 7, 4194.

17 Y. Wang and D. J. Patel, Structure, 1993, 1, 263.

18 A. D. Moorhouse, A. M. Santos, M. Gunaratnam, S. Neidle and J. E. Moses, J. Am. Chem. Soc., 2006, 128, 15972; A. D. Moorhouse, S. Haider, M. Gunaratnam, D. Munnur, S. Neidle and J. E. Moses, Mol. BioSyst., 2008, 4, 629; D. J. Ritson and J. E. Moses, Tetrahedron, 2011, 68, 197.

19 Ligand and oligonucleotide concentrations, and the ratio of the two, were varied and showed that thermal stability of the complexes was dependent on ligand concentration, but not on oligonucleotide concentration and hence intermolecular associations.

20 MD simulations and modelling used a 4 CPU workstation with Fedora 10 running the AMBER 8 suite of programs. Models for the sequences $\mathrm{HT}, \mathrm{HT}^{2}$ and $\mathrm{HT}^{3}$ were constructed using published PDB quadruplex structures with the closest correspondence to the topologies of interest: for the parallel HT structure 2LD8, basket $(2+2) 2 \mathrm{KF} 8$ and 143D, $(3+1)$ hybrid HT structures 2HY9 (hyb1), 2JPZ (hyb2). 